\title{
AVALIAÇÃO DA VIABILIDADE E VIGOR DE SEMENTES DE Anadenanthera peregrina (L.) Speg. SUBMETIDAS AO ENVELHECIMENTO ACELERADO E AO OSMOCONDICIONAMENTO ${ }^{1}$
}

\author{
Daniel Santos Pinho², Eduardo Euclydes de Lima e Borges ${ }^{3}$ e Cláudia Aparecida Pontes ${ }^{4}$
}

\begin{abstract}
RESUMO - O objetivo deste trabalho foi avaliar o vigor e viabilidade de sementes de Anadenanthera peregina submetidas ao envelhecimento acelerado e ao osmocondicionamento. As sementes foram acondicionadas em caixas tipo "gerbox" com uma tela de alumínio separando-as do fundo do gerbox, onde se adicionou água destilada. As caixas foram mantidas em câmara de envelhecimento nas temperaturas de 40,50 e $60{ }^{\circ} \mathrm{C}$, durante 24 , 48, 72 e 96 h. Para o controle foram utilizadas sementes não submetidas ao envelhecimento. Após cada tempo, as sementes foram submetidas aos seguintes testes: teste de germinação, índice de velocidade de germinação, condutividade elétrica, teste de tetrazólio, osmocondicionamento e avaliação das plântulas. A $40^{\circ} \mathrm{C}$, a porcentagem de germinação, o Índice de Velocidade de Germinação (IVG) e a porcentagem de sementes viáveis pelo teste de tetrazólio decresceram significativamente. Houve incremento significativo da curva de condutividade elétrica à medida que aumentou a permanência das sementes dentro da câmara de envelhecimento. A partir de $96 \mathrm{~h}$ de permanência na câmara de envelhecimento, as sementes perderam toda a viabilidade, assim como aquelas submetidas ao envelhecimento a 50 e $60^{\circ} \mathrm{C}$. Na avaliação das plântulas, todos os parâmetros analisados decresceram à medida que as sementes permaneceram na câmara de envelhecimento por mais tempo, com exceção da porcentagem de plântulas anormais e do peso fresco da raiz, que tiveram incremento nos seus valores.
\end{abstract}

Palavras-chave: Envelhecimento precoce, Anadenanthera e Viabilidade.

\section{VIABILITY AND VIGOUR EVALUATION OF THE Anadenanthera peregrina (L.) Speg. SEEDS SUBMITTED TO THE ACCELERATED AGING AND OSMOPRIMING}

\begin{abstract}
The aim of this experiment was to evaluate the effect of the accelerated aging in the vigor and viability of Anadenanthera peregrina seeds. For the accelerated aging test, the seeds were conditioned in "gerbox" boxes with an aluminum screen separating the seeds from the bottom of the box. Distilled water was added into the bottom and, after that, the boxes were conditioned in aging chambers under temperatures of 40,50 and $60^{\circ} \mathrm{C}$, during periods of 24, 48, 72 and 96 hours. Seeds not submitted to the aging process were used as the control. After each period the seeds were submitted to the following tests: standard germination test, germination speed index, electric conductivity, tetrazolium test, osmopriming and seedling evaluation. Under $40^{\circ} \mathrm{C}$, the percentage of germination, the IVG and the percentage of viable seeds for the tetrazolium test decreased significantly. A significant increase in the electric conductivity curve was noticed, as the period in the aging chamber increased. The seeds lost all their viability when submitted to the aging chamber from periods longer than 96 hours, as well as those submitted to temperatures of $50^{\circ}$ and $60^{\circ} \mathrm{C}$. In the seedling evaluation, all the parameters analyzed decreased as the seeds stayed in the aging chamber for longer periods, except the percentage of abnormal seedlings and the cool weight of the root, which both increased.
\end{abstract}

Keywords: Accelerated aging, Anadenanthera and Viability.

\footnotetext{
${ }^{1}$ Recebido em 24.05.2008 e aceito para publicação em 02.03.2010.

${ }^{2}$ Instituto Brasileiro de Meio Ambiente e Recursos Naturais Renováveis, IBAMA, Brasil. E-mail: < danielspinho@hotmail.com>.

${ }^{3}$ Universidade Federal de Viçosa, UFV, Brasil. E-mail: <elborges@ufv.br>.

${ }^{4}$ Instituto Federal de Minas Gerais, Campus São João Evangelista, Minas Gerais. E-mail: <pontesac@gmail.com>.
} 


\section{INTRODUÇÃO}

O teste de envelhecimento acelerado foi desenvolvido para estimar a longevidade de sementes armazenadas (RAVIKUMAR et al., 2002) e identificar diferenças na qualidade fisiológica de lotes comercializáveis, principalmente os que possuem poder germinativo semelhante de sementes submetidas à temperatura e umidade relativa elevadas. Outros usos indicados do teste de envelhecimento precoce são as avaliações dos potenciais de emergência das plântulas no campo e de armazenamento, em programas de controle de qualidade e em auxílio a métodos de seleção durante o melhoramento de plantas (KRYZANOWSKI et al., 1999).

O teste de envelhecimento acelerado, desenvolvido por DELOUCHE (1965) para estimar o potencial relativo de armazenamento, baseia-se no princípio de que a taxa de deterioração das sementes é aumentada pela sua exposição a níveis elevados de temperatura e umidade relativa. Assim, verificou-se que lotes com baixo vigor apresentavam maior queda na viabilidade quando submetidos a essa situação (KRYZANOWSKI et al., 1999).

Sementes mais vigorosas possuem a capacidade de produzir plântulas normais, apresentando germinação mais rápida e elevada após serem submetidas ao teste de envelhecimento acelerado, enquanto as com baixo vigor mostraram baixa viabilidade (GARCIA et al., 2004).

Por ser um teste relativamente de fácil execução em laboratório, o teste de envelhecimento acelerado vem sendo empregado na determinação do vigor de diversas espécies de hortaliças e de grandes culturas, podendo apresentar limitações para algumas espécies (RODO et al., 2000). O emprego do teste tem se mostrado bastante promissor em espécies florestais tropicais (RAMOS et al., 1992; CHAISURISRI et al., 1993; CAMARGO et al., 2000 e GARCIA et al., 2004), onde, segundo esses autores, o teste mostrou-se adequado na avaliação da qualidade fisiológica dos lotes.

Comumente conhecida como angico, angicovermelho, angico-do-morro, angico-branco, paricá, paricáde-terra firme, a A. peregrina é pioneira, pertencente à família Leguminosae-Mimosoideae (Mimosaceae) (LORENZI, 1998), e com ampla distribuição geográfica. Ainda segundo esse autor, ela ocorre em florestas semidecíduas e na transição com o Cerrado, nos Estados do Tocantins, de Goiás, da Bahia, de Minas Gerais, do Rio de Janeiro, de São Paulo, de Mato Grosso e do Mato Grosso do Sul.
De acordo com COSTA et al. (2003), a época de maturação dos frutos e sementes de A. peregrina na região da Chapada dos Guimarães coincide com o final da estação seca, quando diversas espécies do Cerrado estão com poucas folhas. A espécie apresenta frutos secos, deiscentes, sem atrativos para os animais. São legumes achatados que se abrem apenas de um lado, expondo suas sementes, que caem imediatamente após a deiscência dos frutos. As sementes são leves, achatadas, escuras, discoides, de formato orbicular. A sua morfologia permite que sejam dispersas pelo vento forte a curtas distâncias, porém, com maior frequência, estabelecendo-se junto da árvore-matriz, o que deixa caracterizada para essa espécie a síndrome barocórica (COSTA et al., 2003).

A. peregrina provê $90 \%$ de exsudados consumidos por grupos de Callithrix flaviceps acompanhados na Reserva Biológica de Caratinga, MG, sendo a fonte preferida de goma (CORRÊA et al., 2000), além de ser indicada para recuperação de áreas degradadas por mineração (ARAÚJO et al., 2006).

O objetivo deste trabalho foi avaliar o vigor e viabilidade de sementes de $A$. peregina submetidas ao envelhecimento acelerado e ao osmocondicionamento.

\section{MATERIAIS E MÉTODOS}

Foram utilizadas sementes de $A$. peregrina colhidas na região de Viçosa, MG, em setembro de 2005, e armazenadas no Laboratório de Análise de Sementes Florestais (LASF) da Universidade Federal de Viçosa (UFV) em câmara fria a aproximadamente $5^{\circ} \mathrm{C}$ e $60 \%$ de umidade relativa até a data do início dos trabalhos, no mês de janeiro. O teor de água inicial das sementes foi determinado pelo método da estufa a $105 \pm 3^{\circ} \mathrm{C}$ por 24 h com quatro repetições de 25 sementes, de acordo com BRASIL (1992).

Para o teste de envelhecimento acelerado, as sementes foram acondicionadas em caixas tipo "gerbox" com uma tela de alumínio separando as sementes do fundo do gerbox, onde se adicionou água destilada. As caixas foram acondicionadas em câmara de envelhecimento nas temperaturas de 40,50 e $60{ }^{\circ} \mathrm{C}$, durante os períodos de 24, 48, 72 e 96 h. Para o controle foram utilizadas sementes coletadas e não submetidas a nenhum tratamento. Após o envelhecimento, as sementes foram separadas em dois grupos, sendo um deles submetidos ao osmocondicionamento seguido 
dos testes de germinação, índice de velocidade de germinação, de condutividade elétrica e de tetrazólio. O outro grupo não foi submetido ao osmocondicionamento, mas sim aos demais testes citados.

\subsection{Osmocondicionamento}

Sementes de $A$. peregrina foram embebidas em água destilada (potencial de $0 \mathrm{MPa}$ ), e em solução de polietilenoglicol (PEG 6000) nos potenciais de $-0,2,-0,4,-0,6$ e -0,8 MPa por $24 \mathrm{~h}$. Foram utilizadas quatro repetições de 25 sementes cada, distribuídas em placas de Petri esterilizadas e forradas com duas folhas de papel-filtro umedecidas com $12 \mathrm{~mL}$ das soluções de teste. Depois de pré-condicionadas, as sementes foram secadas em ambiente de laboratório por 24 h e colocadas para germinar em câmara de germinação a $25^{\circ} \mathrm{C}$. As avaliações foram realizadas a cada 24 horas até o quinto dia. A curva de embebição foi determinada pela pesagem inicial das sementes antes da embebição e, em seguida, pela pesagem após 0,$5 ; 1 ; 2 ; 3 ; 4 ; 5 ; 6 ; 7 ; 8 ; 24$; e 48 h de embebição em água destilada ou em solução de polietilenoglicol (PEG 6000), nos potenciais de $-0,2,-0,4,-0,6$ e -0,8 MPa. Antes de cada pesagem, as sementes foram secas com papel absorvente e, posteriormente, recolocadas nas respectivas placas, em água destilada ou na solução. Com os valores consecutivos de pesagem foi calculada a porcentagem de ganho de água em relação ao peso inicial das sementes, a fim de estabelecer as curvas de embebição. A partir dos resultados apresentados no osmocondicionamento e na curva de embebição, as sementes de $A$. peregrina foram embebidas em solução de PEG 6000 a -0,4 MPa por 24 h. Foram utilizadas quatro repetições de 25 sementes cada, distribuídas em placas de Petri esterilizadas e forradas com duas folhas de papel-filtro umedecidas com $12 \mathrm{~mL}$ das soluções de teste. Depois de pré-condicionadas, as sementes foram secas em condições de laboratório por 24 h antes de serem submetidas aos demais testes.

\subsection{Teste de germinação}

As sementes foram imersas em solução de captan 0,5\% por 60 seg. Em seguida foram colocadas para germinar em caixas tipo "gerbox" forradas com papelfiltro umedecido com água destilada até o ponto de saturação. Foram postas para germinar 25 sementes por repetição, tendo cada tratamento quatro repetições. O teste foi conduzido em BOD à temperatura constante de $25^{\circ} \mathrm{C}$ e luz constante, fornecida por quatro lâmpadas fluorescentes $(20 \mathrm{~W})$. As avaliações foram realizadas a cada 24 h até o quinto dia, sendo consideradas germinadas as sementes com protrusão da radícula.

\section{3. Índice de Velocidade de Germinação (IVG)}

Este índice foi calculado de acordo com a fórmula descrita por Maguirre (1962), em que G é o número de sementes germinadas por dia e $\mathrm{N}$, o número de dias decorridos.

$$
\mathrm{IVG}=\Sigma \mathrm{G}_{\mathrm{i}} / \mathrm{N}_{\mathrm{i}}
$$

\subsection{Teste de Condutividade Elétrica}

As sementes de A. peregrina foram embebidas em 75 mL de água destilada e colocadas em câmara tipo BOD a $25^{\circ} \mathrm{C}$, no escuro total. Após 24 h foi medida a condutividade elétrica da solução restante em condutivímetro. Foram utilizadas quatro repetições de 25 sementes para o teste (SANTOS e PAULA, 2005).

\subsection{Teste de Tetrazólio}

Quatro repetições de 25 sementes de A. peregrina foram pré-condicionadas em imersão em água destilada por $24 \mathrm{~h}$ a $25^{\circ} \mathrm{C}$. Posteriormente, o tegumento das sementes foi retirado e os embriões, colocados em copos plásticos e submersos em solução de tetrazólio (2,3,5-trifenil cloreto de tetrazólio) (pH 6,5) 0,1\%, sendo mantidos no escuro à temperatura de $30^{\circ} \mathrm{C}$ por 24 h.Após esse período, os embriões foram lavados em água corrente e deixados em água destilada por no máximo cinco horas. Os embriões submetidos ao teste foram cortados longitudinalmente, avaliando-se a intensidade da coloração, presença de áreas leitosas, aspectos dos tecidos e localização da coloração em relação aos cotilédones e ao eixo embrionário, de acordo com PINHO (2007).

\subsection{Avaliações das Plântulas}

Foram utilizadas quatro repetições de 25 sementes cada, provenientes dos diferentes períodos de envelhecimento. As sementes foram semeadas a $2 \mathrm{~cm}$ de profundidade em substrato de areia lavada e peneirada, em bandejas de plástico, mantidas sob condições de laboratório em temperatura ambiente. O experimento foi irrigado todos os dias e a contagem das plântulas com altura superior a $2 \mathrm{~cm}$, realizada diariamente até o $15^{\circ}$ dia, avaliando-se a porcentagem final de plântulas emergidas, o índice de velocidade de emergência das plântulas, as porcentagens de plântulas normais e anormais, o comprimento e os pesos das massas frescas e secas da parte aérea e da radícula das plântulas.

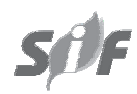

Revista Árvore, Viçosa-MG, v.34, n.3, p.425-434, 2010 
Utilizou-se o delineamento inteiramente casualizado (DIC), para as análises de variância (ANOVA) e de regressão. Na análise de regressão foram testados os modelos lineares e quadráticos, sendo selecionado aquele com maior valor do coeficiente de determinação $\left(\mathrm{R}^{2}\right)$.

\section{RESULTADOS E DISCUSSÃO}

Os resultados de porcentagem de germinação das sementes de $A$. peregrina condicionadas em soluções de PEG 6000 são apresentados na Figura 1. Foram encontradas diferenças significativas dos valores de porcentagem de germinação, e aquelas mantidas em potencial de -0,4 MPa apresentaram o maior valor (90\%). No potencial de -0,6 MPa, observou-se queda nos valores. O condicionamento de sementes ajuda na reparação das membranas que tenham sido desestruturadas durante a secagem, no período de maturação das sementes (McDONALD, 1999). O osmocondicionamento de sementes é também importante para populações naturais de sementes, reduzindo o tempo de germinação, sendo considerada vantagem para ambientes onde as condições ideais de germinação são raras, como em regiões áridas (ADAMS, 1999).

As curvas de embebição de sementes de $A$. peregrina em água destilada e em diferentes concentrações de PEG 6000, em que as sementes de $A$. peregrina apresentaram teor de água inicial de 9,95\%, em média, são apresentadas na Figura 2. Nas sementes embebidas em água, o padrão da curva mostrou no modelo trifásico proposto por Bewley e Black (1994), em que na fase I ocorre

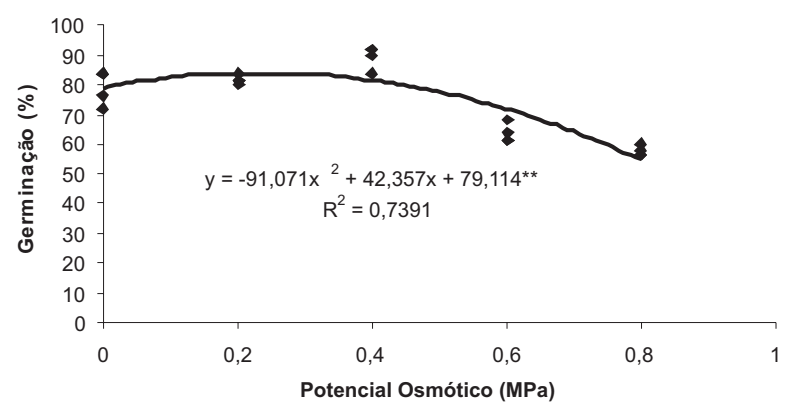

Figura 1 - Germinação de sementes de $A$. peregrina submetidas a diferentes potenciais osmóticos induzidos por concentrações de PEG 6000.

Figure 1 - Germination of A. peregrina seeds subjected to different osmotic potencials of PEG 6000.

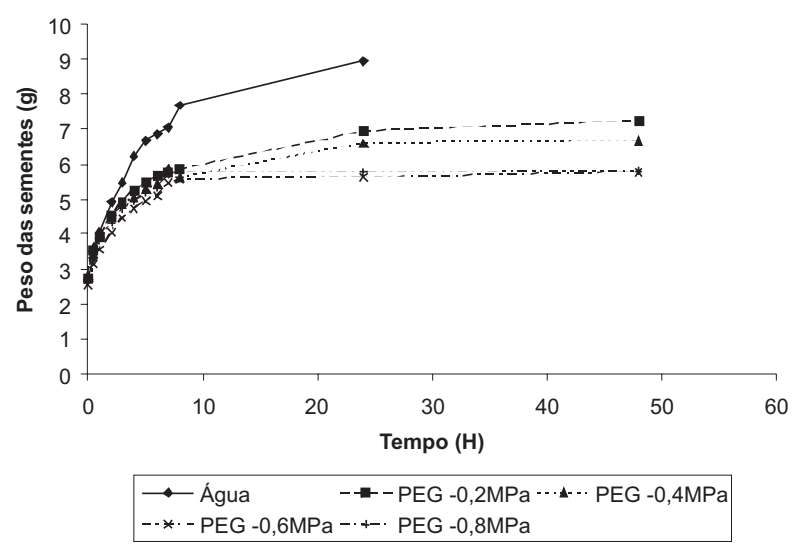

Figura 2 - Variação no peso das sementes relativa à embebição de sementes de $A$. peregrina em água destilada e em diferentes concentrações de PEG 6000. As setas indicam protrusão da radícula.

Figure 2 - Weight variation of A. peregrina seeds in distilled water and in different concentrations of PEG 6000. The arrows indicate germination.

intensa entrada de água devida, a princípio, à diferença de potencial mátrico dos tecidos das sementes. Na fase II, a absorção é reduzida e na fase III ele aumenta novamente. As sementes embebidas em solução de PEG 6000 permaneceram na fase II do modelo. Em todas as curvas, a fase I ocorreu nas primeiras $8 \mathrm{~h}$ de embebição, e na fase II a absorção de água foi reduzida nos potenciais de -0,2 $\mathrm{MPa}$ e -0,4 $\mathrm{MPa}$, enquanto nos potenciais de -0,6 $\mathrm{MPa}$ e -0,8 MPa ela foi nula. A protrusão da radícula iniciou em diferentes períodos, de acordo com a concentração de PEG 6000. Em água destilada, a protrusão ocorreu em 24 h, nas concentrações de -0,2 e -0,4 MPa em 48 h e nas demais concentrações não houve protrusão. Com o decréscimo do potencial osmótico, a fase II do processo de absorção de água foi prolongada, implicando atraso na emergência da radícula (JELLER et al., 2003).

Os valores de porcentagem de germinação, IVG, condutividade elétrica e teste de tetrazólio de sementes de $A$. peregrina submetidas ao envelhecimento precoce a $40^{\circ} \mathrm{C}$, nos diversos períodos, estão apresentados na Figura 3. A porcentagem de germinação, o IVG e a porcentagem de sementes viáveis pelo teste do tetrazólio caíram significativamente à medida que aumentou a permanência das sementes dentro da câmara de envelhecimento. Na condutividade elétrica, notou-se incremento significativo da curva. 
a

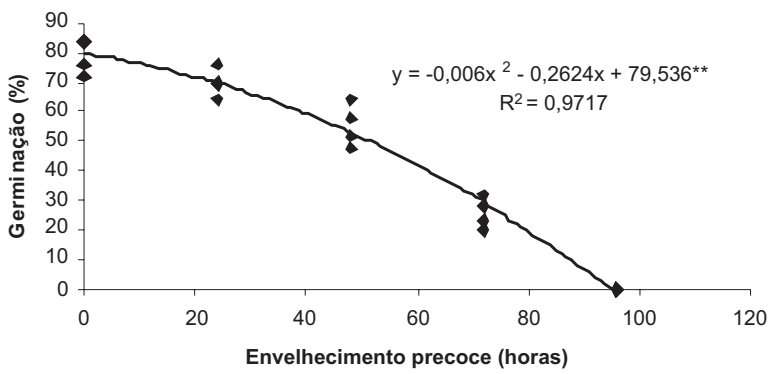

C

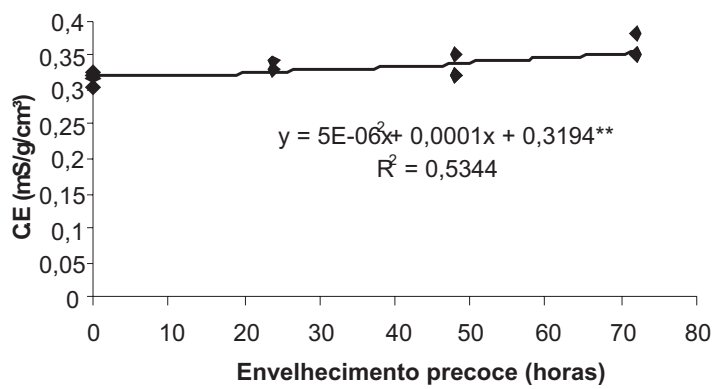

b

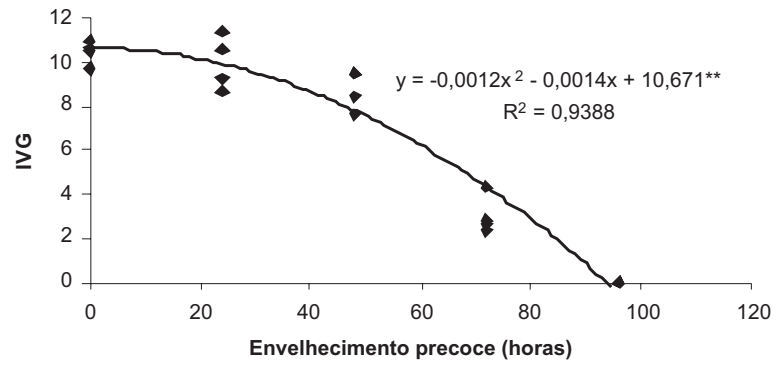

d

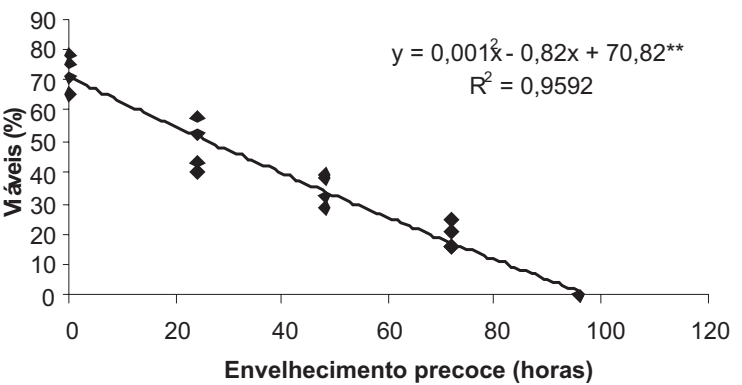

Figura 3 - Porcentagem de germinação (a), Índice de Velocidade de Germinação (IVG) (b), condutividade elétrica (c) e viabilidade pelo teste de tetrazólio (d) de sementes de A. peregrina submetidas ao envelhecimento acelerado a $40^{\circ} \mathrm{C}$ por $0,24,48,72$ e 96 h.

Figure 3 - Percentage of germination (a), speed germination index (IVG) (b), electric conductivity (c) and tetrazolium test viability (d) of A. peregrina seeds submitted to the accelerated aging under $40^{\circ} \mathrm{C}$ for $0,24,48,72$ and 96 hours.

Após 96 h de permanência na câmara de envelhecimento, as sementes perderam a viabilidade, assim como aquelas submetidas ao envelhecimento a 50 e $60^{\circ} \mathrm{C}$, independentemente do período de tempo.

A degradação de metabólicos essenciais, incluindo a perda de reservas, é um dos fatores responsáveis mais importantes pela perda da viabilidade das sementes (RAVIKUMAR et al., 2002). De acordo com GOEL et al. (2003), várias reações oxidativas são geradas durante o envelhecimento das sementes causando a peroxidação dos lipídios e induzindo peroxidação não enzimática, que tem o potencial de danificar membranas, sendo essa a maior causa da deterioração de sementes armazenadas.
Na Figura 4 são apresentados os valores de germinação, IVG, condutividade elétrica e de viabilidade pelo teste de tetrazólio das sementes de A. peregrina submetidas ao envelhecimento precoce e osmocondicionadas em solução de PEG 6000 (-0,4 Mpa). Esse potencial foi escolhido nos testes de osmocondicionamento por melhor potencializar a germinação, assim como observado na Figura 1.Aporcentagem de germinação, oIVG eaporcentagem de sementes viáveis pelo teste de tetrazólio decresceram significativamente à medida que o tempo de permanência na câmara de envelhecimento aumentou para a condutividade elétrica, foi verificado acréscimo significativo da curva.

Considerou-se, portanto, que o osmocondicionamento não reverteu o efeito do envelhecimento. Tal fato não pode ser atribuído ao estresse a que as sementes poderiam estar sendo submetidas com a secagem após o 
a
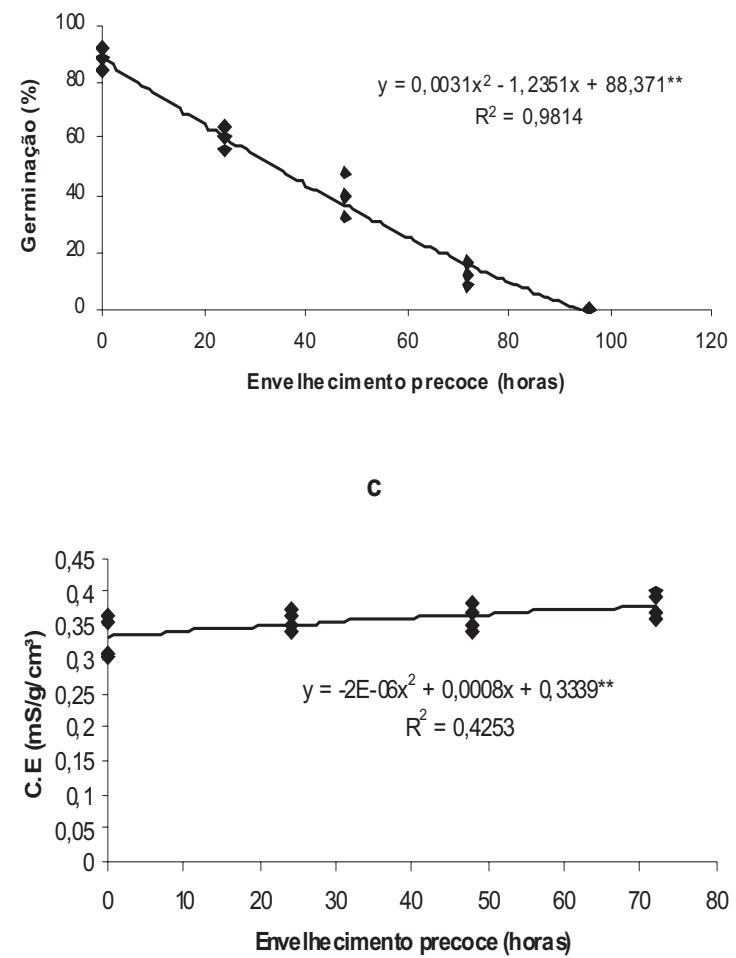

b

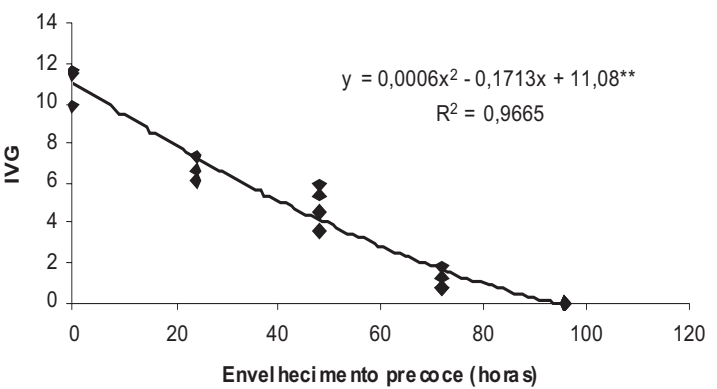

d

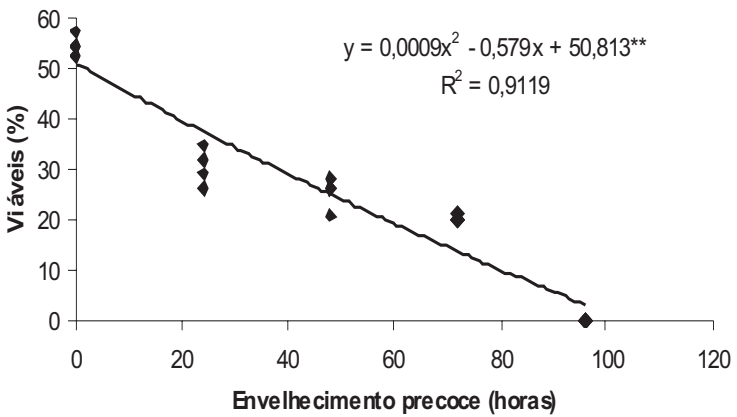

Figura 4 - Germinação (a), índice de Velocidade de Germinação (IVG) (b), Condutividade elétrica (c) e viabilidade pelo teste de tetrazólio (d) de sementes de A. peregrina osmocondicionadas em PEG -0,4 MPa por 24 h após submetidas ao envelhecimento acelerado a $40{ }^{\circ} \mathrm{C}$ por $0,24,48,72$ e $96 \mathrm{~h}$.

Figure 4 - Percentage of germination (a), speed germination index (IVG) (b), electric conductivity (c) and tetrazolium test viability (d) of A. peregrina seeds osmoprimed in PEG -0.4Mpa for 24 hs after being submitted to accelerated aging under $40^{\circ} \mathrm{C}$ for $0,24,48,72$ and 96 hours.

osmocondicionamento, uma vez que aquelas não mantidas no PEG 6000 se comportaram-se de maneira semelhante. Os possíveis mecanismos de recuperação da viabilidade que o osmocondicionamento proporciona em sementes envelhecidas naturalmente se mostraram não eficientes no caso presente.

O aumento da condutividade elétrica pode indicar inabilidade de manutenção da integridade das membranas, resultando em perdas de germinabilidade (CHANG e SUNG, 1998). Em sementes de algodão, a condutividade elétrica das sementes aumentou progressivamente com o tratamento de envelhecimento precoce, refletindo assim a perda de integridade da membrana (GOEL et al., 2003). Ainda segundo os referidos autores, o condicionamento em água reduziu significativamente a condutividade elétrica após o envelhecimento artificial, em comparação com o controle.

A porcentagem de plântulas emergidas, normais e anormais e o índice de velocidade de emergência (IVE) de A. peregrina submetidas ao envelhecimento precoce são apresentados na Figura 5. Observou-se, de modo geral, decréscimo significativo nas porcentagens de plântulas emergidas e de plântulas normais e do índice de velocidade de emergência à medida que aumentou o período de exposição na câmara de envelhecimento. No entanto, houve aumento significativo da porcentagem de plântulas anormais no mesmo período, chegando a 51,85\% quando envelhecidas por $72 \mathrm{~h}$. Resultado semelhante 


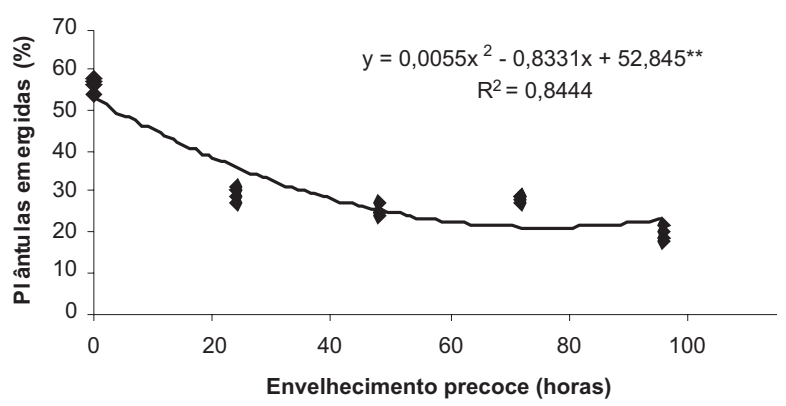

C

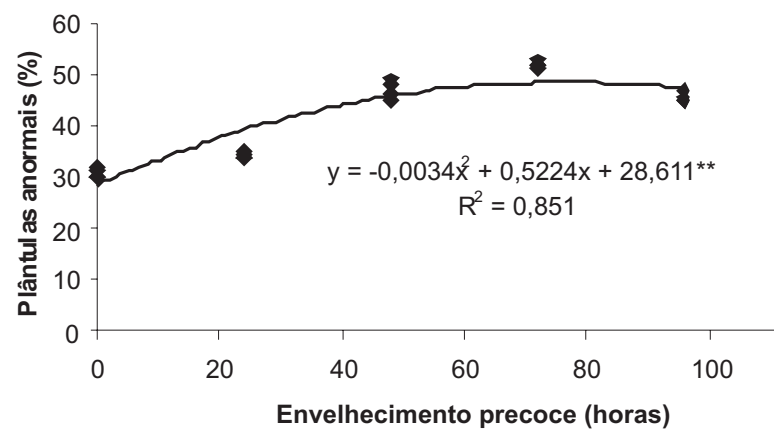

b

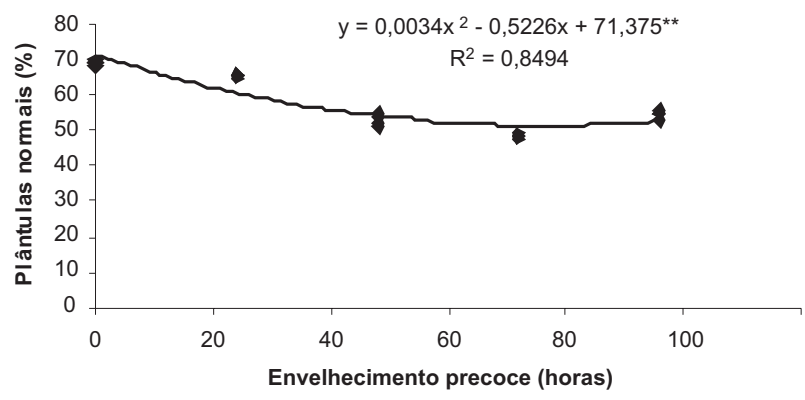

d

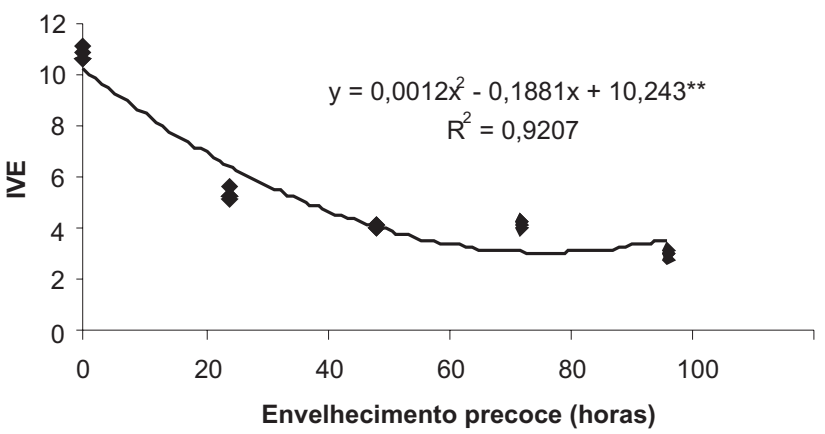

Figura 5 - Porcentagem de plântulas emergidas (a), normais (b) e anormais (c) e índice de velocidade de emergência IVE (d) de plântulas de A. peregrina submetidas ao envelhecimento acelerado a $40^{\circ} \mathrm{C}$ por 0, 24, 48, 72 e $96 \mathrm{~h}$.

Figure 5 - Percentage of seedlings (a), normal (b) and abnormal (c) and emergence speed index IVE (d) of A. peregrina submitted to the accelerated aging under $40^{\circ} \mathrm{C}$ for $0,24,48,72$ and 96 hours.

foi encontrado por Garcia et al. (2004) em sementes de Anadenanthera colubrina, cujo envelhecimento precoce acarretou maior porcentagem de plântulas anormais.

Os comprimentos e as massas fresca e seca da parte aérea e da raiz de plântulas de A. peregrina submetidas ao envelhecimento precoce são apresentados na Figura 6. Verifica-se, nessa figura que em todos os valores, à exceção da massa de madeira fresca da raiz, houve decréscimo significativo à medida que se aumentava o tempo de permanência na câmara de envelhecimento. Com relação à massa fresca da raiz, houve acréscimo significativo nos seus valores. Nas sementes de Chorisia speciosa submetidas a diferentes períodos de envelhecimento precoce, a massa seca da parte aérea das plântulas diminuiu, e a massa seca da parte subterrânea não apresentou diferenças significativas com o aumento do período de permanência na câmara de envelhecimento (FANTI e PEREZ, 2005). Já nas espécies Dypsis lutescens, Euterpe edulis, Phoenix reclinata e Roystonea oleraceae a massa seca da parte aérea não mostrou diferenças significativas entre os períodos de envelhecimento, embora houvessem diferenças significativas entre as espécies. Na massa seca do sistema radicular, tanto entre as espécies quanto entre os períodos de envelhecimento houve diferença significativa. De acordo com NEGREIROS e PEREZ (2004), fatores relacionados intrinsecamente com as sementes, como diferenças entre espécies, nível de vigor, teor de umidade, condições da planta-mãe e local de produção das sementes, são importantes na hora da avaliação do desenvolvimento das plântulas submetidas ao envelhecimento precoce.

Revista Árvore, Viçosa-MG, v.34, n.3, p.425-434, 2010 
a

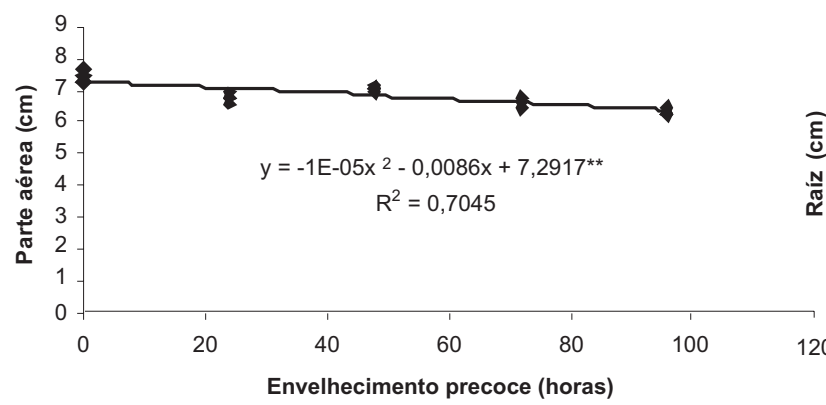

C

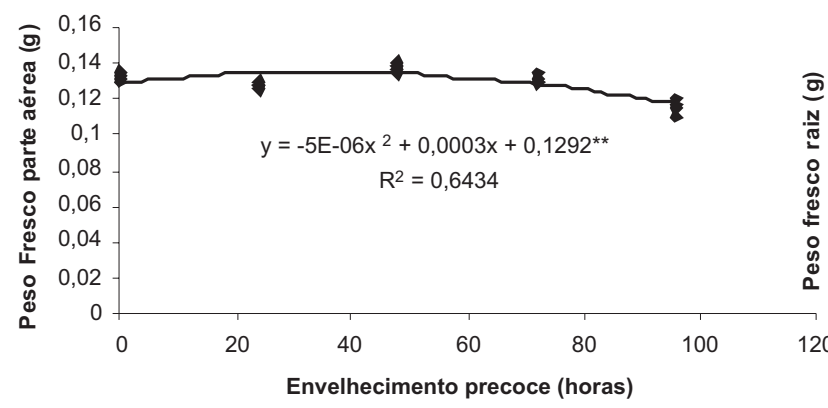

e

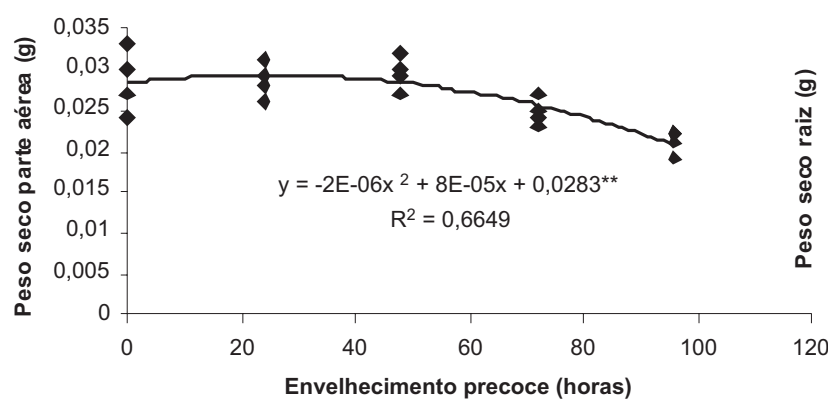

b

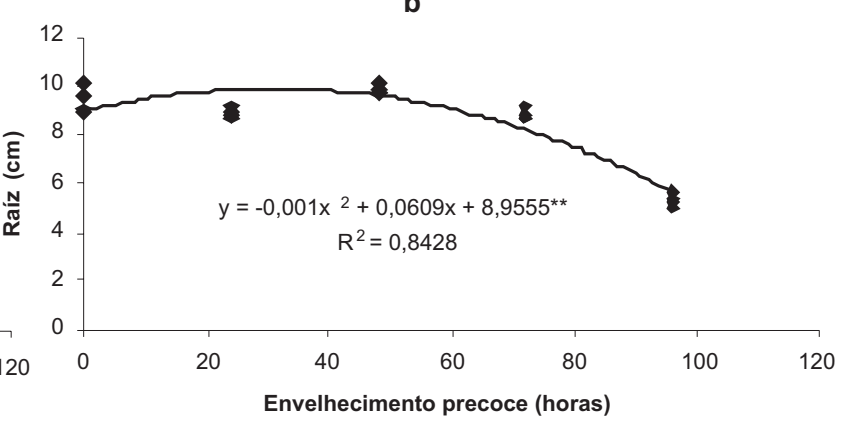

d

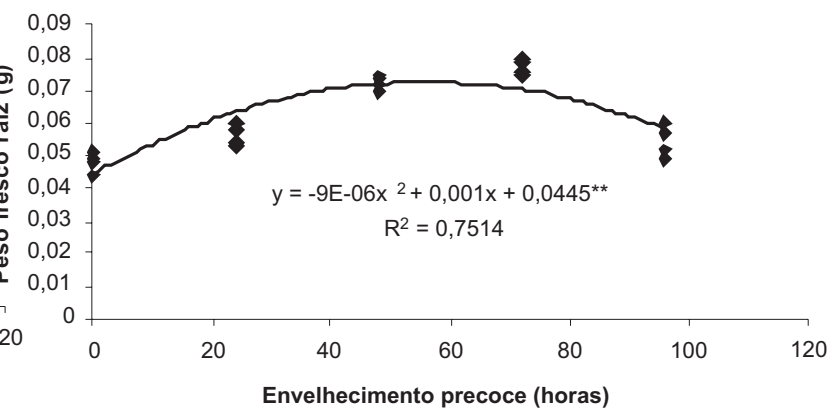

f

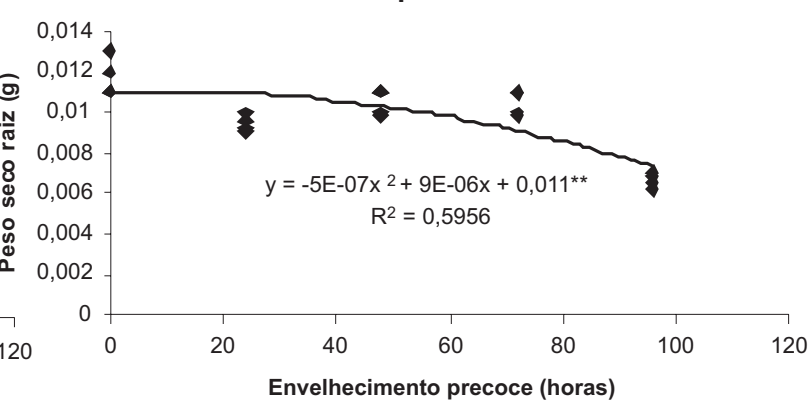

Figura 6 - Comprimento da parte aérea (a) e da raiz (b) e pesos das massas fresca (c e d) e seca (e e f) da parte aérea e da raiz de plântulas de $A$. peregrina submetidas ao envelhecimento acelerado a $40^{\circ} \mathrm{C}$ por $0,24,48,72$ e $96 \mathrm{~h}$.

Figure 6 - Length ( $a$ and $b$ ) and fresh ( $c$ and $d$ ) and dry ( $e$ and f) weight of A. peregrina seedlings' shoot and root submitted to the accelerated aging under $40^{\circ} \mathrm{C}$ for $0,24,48,72$ and 96 hours.

\section{CONCLUSÃO}

A viabilidade e o vigor das sementes de $A$. peregrina foram afetados pelo aumento do tempo de sua permanência na câmara de envelhecimento.

O período de $96 \mathrm{~h}$ de envelhecimento precoce e as temperaturas de 50 e $60{ }^{\circ} \mathrm{C}$ acarretaram na perda total da viabilidade e vigor das sementes de $A$. peregrina.

O osmocondicionamento não foi eficiente na recuperação da viabilidade e vigor das sementes de A. peregrina.

Revista Árvore, Viçosa-MG, v.34, n.3, p.425-434, 2010

\section{REFERÊNCIAS}

ADAMS, R. Germination of Callitris seeds in relation to temperature, water stress, priming, and hydration-dehydration cycles. Journal of Arid Environments, v.43, p.437-448, 1999.

ARAÚJO, F. S. et al. Estrutura da vegetação arbustivo-arbórea colonizadora de uma área degradada por mineração de caulim, Brás Pires, MG. R.Árvore, v.30, n.1, p.107-116, 2006. 
BEWLEY, J. D.; BLACK, M. Seeds: Physiology of development and germination. 2.ed. New York: Plenum Press, 1994. 445p.

BRASIL. Ministério da Agricultura. Regras para análise de sementes. Brasília:1992. 365p.

CAMARGO, M. L. P. et al. Atividade enzimática em plântulas de Eucalyptus grandis provenientes de sementes envelhecidas artificialmente e naturalmente. Ciência Florestal, v.10, n.2, p.113-122, 2000.

CHAISURISRI, K.; EDWARDS, D. C. W.; ELKASSABY, Y. A. Accelerated aging of Sitka Spruce seeds. Silvae Genetica, v.42, n.6, p.303-308, 1993.

CHANG, S. M. \& SUNG, J. M. Deteriorative changes in primed sweet corn seeds during storage. Seed Science Technology, v.26, p.613-626, 1998.

CORRÊA, H. K. M.; COUTINHO, P. E. G.; FERRARI, S. F. Between-year differences in the feeding ecology of highland marmosets (Callithrix aurita and Callithrix flaviceps) in south-eastern Brazil. Joural of Zoology, v.252, NUMERO, p.421-427, 2000.

COSTA, R. B.; CONTINI, A. Z.; MELO, E. S. P. Sistema reprodutivo de Anadenanthera peregrina (L.) Speg e Vochysia haenkiana (Spreng.) Mart. em fragmento de cerrado na Chapada dos Guimarães - MT. Ciência Rural, v.33, n.2, p.305-310, 2003.

DELOUCHE, J. C. An accelerated aging technique for predicting relative storability of crimson clover and tall fescue seed lots. Agronomy

Abstracts, 1965, p.40, 1965.

FANTI, S. C.; PEREZ, S. C. J. G. A. Efeito do envelhecimento precoce no vigor de sementes de Chorisia speciosa St. Hil. - Bombacaceae. Revista Árvore, v.29, n.3, p.345-352, 2005.

GARCIA, L. C.; NOGUEIRA, A. C.; ABREU, D. C. A. Influência do envelhecimento acelerado no vigor de sementes de Anadenanthera colubrina (Vellozo) Brenan - Mimosaceae. Ciência Florestal, v.14, n.1, p.85-90, 2004.
GOEL, A.; GOEL, A. K.; SHEORAN, I. S. Changes in oxidative stress enzymes during artificial ageing in cotton (Gossypium hirsutum L.) seeds. Journal of Plant Physiology, v.160, p.1093-1100, 2003.

JELLER, H.; PEREZ, S. C. J. G. A.; RAIZER, J. Water uptake, priming, drying and storage effects in Cassia excelsa Schrad seeds. Brazilian Journal of Biology, v.63, n.1, p.61-68, 2003.

KRYZANOWSKI, F. C.; VIEIRA, R. D.; FRANÇA NETO, J. B. Vigor de sementes: conceitos e testes. Londrina: ABRATES Associação Brasileira de Tecnologia de Sementes, Comitê de Vigor de Sementes, 1999. 218p.

LORENZI, H. Árvores Brasileiras: manual de identificação e cultivo de plantas arbóreas do Brasil. 2.ed. Nova Odessa: Instituto Plantarum, 1998. 352p.

MAGUIRRE, J. D. Speed of germination-aid in selection and evaluation for seedling emergence and vigor. Crop Science, v.2, n.1, p.176-177, 1962.

McDONALD, M. B. Seed deterioration: physiology, repair and assessment. Seed Science Technology, v.27, p.177-237, 1999.

NEGREIROS, G. F.; PEREZ, S. C. J. G. A. Resposta fisiológica de sementes de palmeiras ao envelhecimento acelerado. Pesquisa Agropecuária Brasileira, v.39, n.4, p.391-396. 2004.

PINHO, D. S. Teste de tetrazólio, envelhecimento acelerado e osmocondicionamento aplicados em sementes de Anadenanthera peregrina (L.) Speg. 2007. 54f. Dissertação (Mestrado em Ciência Florestal) - Universidade Federal de Viçosa, Viçosa, MG, 2007.

RAMOS, A.; BIANCHETTI, A.; MARTINS, E. G. Viabilidade de lotes de sementes de bracatingacomum (Mimosa scabrella Benth.) e de bracatinga-argentina (Mimosa scabrella var. aspericarpa) após teste de envelhecimento precoce. Boletim de Pesquisa Florestal, v. 24/25, p.79-82, 1992.

RAVIKUMAR, R. et al. Seed viability and biochemical changes associated with accelerated ageing in Dendrocalamus strictus seeds. Biologia Plantarum, v.45, n.1, p.153-156, 2002.

Revista Árvore, Viçosa-MG, v.34, n.3, p.425-434, 2010 
RODO, A. B.; PANOBIANCO, M.; MARCOS

FILHO, J. Metodologia alternativa do teste de envelhecimento acelerado para sementes de cenoura. Scientia Agrícola, v.57, n.2, p.289292, 2000.
SANTOS, S. R. G.; PAULA, R. C. Teste de condutividade elétrica para avaliação da qualidade fisiológica de sementes de Sebastiania commersoniana (Bail) Smith \& Downs Euphorbiaceae. Revista Brasileira de Sementes, v. 27, n.2, p.136-145, 2005. 